\title{
Generalized edema and heart failure caused from hypothyroidism and ferrous agent for hypochromic anemia
}

\begin{abstract}
The patient was an 85-year-old female who has been treated for hypertension and atrial fibrillation (Af). She has visited outpatient clinic and has received regularly general blood tests for every six months. Hemoglobin $(\mathrm{Hb})$ level was stable as 11.2-12.3 g/dL and MCV 88fL from 2017, but it decreased suddenly to $5.2 \mathrm{~g} / \mathrm{dL}$ and $64 \mathrm{fL}$ in Sept 2020. She did not feel any symptoms or signs. Further evaluations revealed that occult blood in stool and upper and endoscopic exams were negative. About 40 days after starting sodium ferrous citrate, she developed edema anasarca, bilateral pleural effusion and heart failure. Laboratory test showed hypothyroidism, and then the administration of thyroid hormone and diuretics brought her early improvement. As to this impressive case report, general clinical progress and some discussion of the relationship among anemia, edema anasarca, heart failure and hypothyroidism would be described.
\end{abstract}

Keywords: edema, heart failure, hypothyroidism, ferrous citrate, anemia
Volume 9 Issue 2 - 202 I

\author{
Naoki Kondo,' Hiroshi Bando, 1,2,3 Shigeki \\ Hatakeyama,' Junji Morita,' Kazuki \\ Sakamoto,' Tomoya Ogawa,' Noboru \\ Iwatsuki' \\ 'Sakamoto Hospital, Higashi Kagawa city, Kagawa, Japan \\ ${ }^{2}$ Tokushima University/Medical Research, Tokushima, Japan \\ ${ }_{3}^{3}$ apan Low Carbohydrate Diet Promotion Association, Kyoto, \\ Japan
}

Correspondence: Hiroshi Bando, MD, PhD, FACP,Tokushima University /Medical Research, Nakashowa I-6I, Tokushima 7700943 Japan, Tel +8I-90-3 I87-2485,

Email pianomed@bronze.ocn.ne.jp

Received: April 13, 2021 | Published: May 03, 202 I

\section{Introduction}

In recent years, common diseases have been increasing in developed countries and also developing countries. It has been necessary to maintain a patient-oriented standpoint and respond the situation in any clinic and hospital. ${ }^{1}$ Furthermore, to take appropriate management for the patients with various diseases and health problems in daily clinical care. ${ }^{2}$ The authors have continued adequate medical practice in a wide range of fields in our hospital. ${ }^{3}$ They include Atherosclerotic Cardiovascular Disease (ASCVD), chronic heart failure (CHF), chronic kidney disease (CKD), cerebrovascular accident (CVA), metabolic syndrome, diabetes, and others. ${ }^{4,5}$

Among them, edema has been common symptom and sign, which is widely observed in patients with various disease states. The pathophysiological causes include cardiovascular, renal, hormonal, metabolic, neurological, nutritional factors and so on. ${ }^{6}$ The definition of edema would be a palpable swollen lesion on the body that is produced from some expansion of the fluid volume in the interstitial tissue. The fluid accumulation in the interstitial tissue may be brought from the increased capillary filtration of the fluid taken out related to lymphatic drainage. ${ }^{7}$ If edema occurs in generalized and massive degree, it has been called anasarca. Such situation can be found from various clinical situations including renal failure, heart failure, impaired function of lymphatic system. In clinical practice, edema may be usually apparent, when the amount of interstitial volume becomes more than 2.5 to 3 liters. ${ }^{8}$

Patients with primary hypothyroidism are commonly found in clinical practice and are often treated in lots of clinics and hospitals. However, clinical cases which are related to serous exudate are rarely seen in routine practice. ${ }^{9}$ The organs detected effusions are observed in pericardial effusion, pleural effusion, ascites, and generalized portions of face, trunk, and extremities. ${ }^{10}$

During our actual daily practice of medicine, we have experienced a meaningful and interesting case. The patient was an elderly female, and developed subacute anemia of unknown cause. After several weeks of treatment, she developed generalized edema and heart failure. A further hormonal evaluation revealed the presence of hypothyroidism, in which related symptoms and signs were alleviated by administration of thyroid hormone. Her clinical progress and some discussions will be described in this article.

\section{Case presentation}

\section{Medical history}

The patient was an 85-year-old female who was previously on medication for hypertension and atrial fibrillation (Af) for years. She has continued regular life without particular accident or medical or health problems. As to the past history, she has not detected to have diabetes, dyslipidemia, hyperuricemia, metabolic syndrome, locomotive syndrome, or cerebrovascular, respiratory gastrointestinal diseases.

She has visited outpatient clinic and has received regularly general blood tests for every six months. From Aug 2017, the value of hemoglobin has been stable from $11.2 \mathrm{~g} / \mathrm{dL}$ to $12.3 \mathrm{~g} / \mathrm{dL}$. Examination in Sept 2020 showed a sudden drop in $\mathrm{Hb}$ level from $11.2 \mathrm{~g} / \mathrm{dL}$ to $5.2 \mathrm{~g} / \mathrm{dL}$ and MCV from $88 \mathrm{fL}$ to $64 \mathrm{fL}$. In this regard, she did not feel any particular physical changes such as fatigue or palpitations. Furthermore, she also had no unusual episodes, such as changes in her stools, nausea, abdominal pain, or other symptoms.

Therefore, the existence of gastrointestinal (GI) bleeding was suspected and further evaluation was immediately started. First, fecal occult blood was negative in twice. Next, we planned endoscopy of the upper gastrointestinal tract. The patient was formerly working as a nurse, and she currently hopes to prioritize her life policy compared to medical scrutiny. Then, we have explained the necessary reason of examination many times. At last, she obeyed the recommendation 
and received the endoscopic examinations of upper and lowers gastrointestinal tracts. Mild gastroesophageal reflux disease (GERD) was noted, but no suspicious bleeding lesions were detected in upper and lower GI tracts. No significant changes were observed in the abdominal CT. For pulse wave test, ABI was normal 1.15 and 1.09 bilaterally. From the above, the cause of acute onset bleeding was not clarified. Consequently, sodium ferrous citrate (SFC) $\left(\right.$ Ferromia $\left.^{\mathrm{R}}\right) 50$ mg 1T and rebamipide $\left(\right.$ Mucosta $\left.^{\mathrm{R}}\right) 100 \mathrm{mg} 1 \mathrm{~T} /$ day were started as the treatment of hypochromic anemia from late Dec 2020.

She developed fatigue and anasarca from the end of Jan 2021, and visited our clinic in early Feb 2021. She did not complain of chest discomfort or dyspnea on exertion.

\section{Physical and laboratory examination findings}

Examination revealed severe edema throughout the body, including the face and extremities. Atrial fibrillation (Af) and lower voltage findings were observed on the electrocardiogram (ECG) (Figure 1). $\mathrm{SpO} 2$ was $98-99 \%$. Chest XP showed moderate pleural effusion in both lungs associated with bilateral vague cost-phrenic angles, which was much different from the previous X-P (Figures 2a, 2b). Based on the above, she was diagnosed with an acute exacerbation of chronic heart failure and was immediately hospitalized. The progress diagram of this example described above is shown in Figure 3, which revealed the changes in $\mathrm{Hb}$ values for recent years.

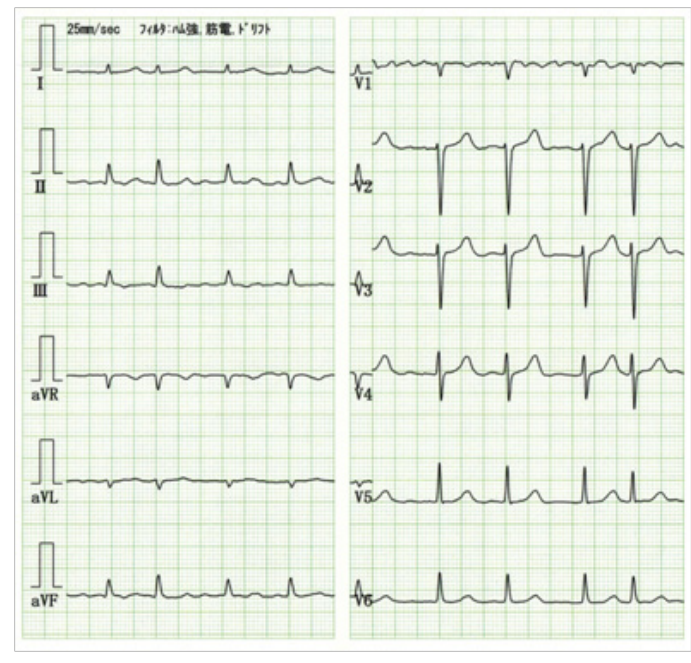

Figure I Electrocardiogram.

Af and low voltage are detected on admission.

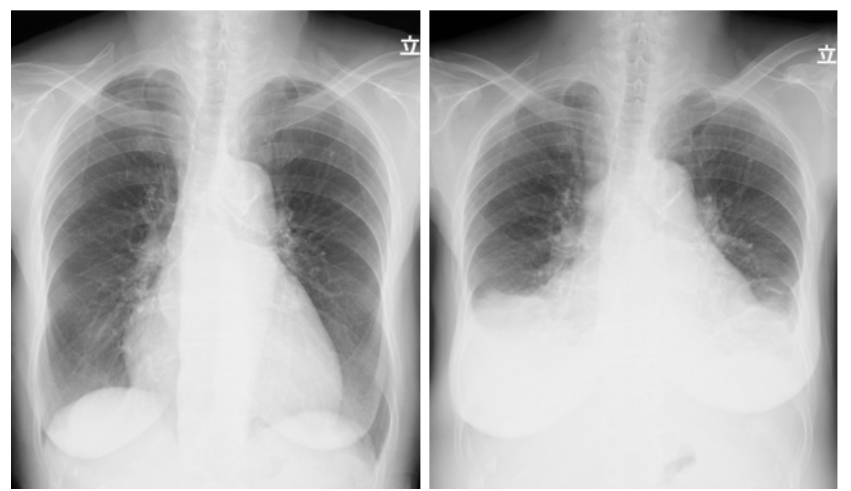

Figure 2 Comparison of the chest X-ray. 2a: unremarkable findings in stable period on May, 2020, 2b: bilateral pleural effusion in admission on Feb, 202I.

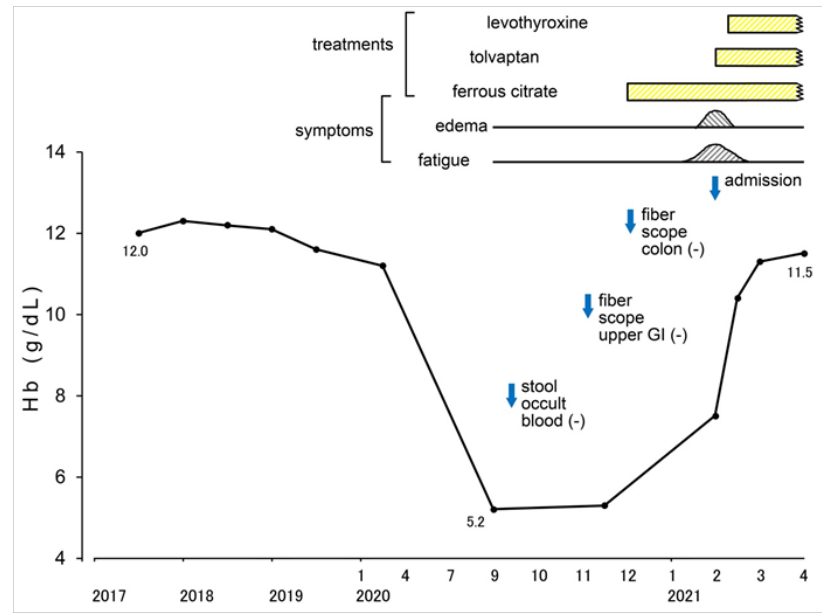

Figure 3 Clinical progress of the case.

$\mathrm{Hb}$ level was stable formerly, and increasing now for last few months.

Vitals showed pulse $88 / \mathrm{min}$, BP $146 / 90 \mathrm{mmHg}$, BT 36.8 centigrade, respiration normal, $\mathrm{SpO}_{2} 98 \%$ in room air, and consciousness was alert. Chest showed that no significant murmurs in the heart and rather weaker breath sound in the lung. Abdomen revealed flat and soft with ordinary bowel sound. No abnormalities were observed in neurological examination.

Laboratory findings on admission and the changes in the data from before were summarized in Table 1. Among them, the important results included $\mathrm{Hb} 7.5 \mathrm{~g} / \mathrm{dL}, \mathrm{Cr} 0.6 \mathrm{mg} / \mathrm{dL}, \mathrm{Na} 148 \mathrm{mEq} / \mathrm{L}, \mathrm{K} 3.7 \mathrm{mEq} / \mathrm{L}$, NTPro BNP 2596pg/mL (-125). When the thyroid function was checked, hypothyroidism was found with free $\mathrm{T}_{3} 1.9 \mathrm{ng} / \mathrm{mL}(2.3-4.3)$ and TSH $9.4 \mu \mathrm{IU} / \mathrm{mL}(0.5-5.0)$.

The following results were obtained by echocardiography. The left ventricular septal diameter (FSD) was $36 \mathrm{~mm}$, the left ventricular septal diameter (LVSD)/posterior wall diameter (LVPWD) was $11 \mathrm{~mm} / 11 \mathrm{~mm}$, the left ventricular diameter shortening rate was $30 \%$, the left ventricular ejection fraction (LVEF) was $57 \%$, and the left ventricular diameter (LVD) was $47 \mathrm{~mm}$. As for the findings, no abnormality was found in the wall movement of the left ventricle, and the contractility of the left ventricle was maintained. Dilation of the left bunch is observed. Slight mitral regurgitation (MR) and aortic regurgitation (AR) are observed.

\section{Medical problems and Prescription}

From the above, the medical problems in this case can be summarized as follows. \#1 hypertension, \#2 Atrial fibrillation (Af), mitral regurgitation (MR), aortic regurgitation (AR), \#3 acute exacerbation of chronic heart failure, \#4, hypochromic anemia, \#5 possible bleeding of gastrointestinal tract, \#6 hypothyroidism, \#7 Gastroesophageal reflux disease (GERD). After admission, her fatigue and edema were improved for short periods by the administration of thyroid hormone and diuretics, and she was discharged in a week.

As regards to her medication before the hospitalization, she has continued Nifedipine (Adalat $\mathrm{CR}^{\mathrm{R}}$ ) $10 \mathrm{mg} 1 \mathrm{~T}$ from spring to summer and Nifedipine CR (Adalat $\mathrm{CR}^{\mathrm{R}}$ ) $20 \mathrm{mg} 1 \mathrm{~T}$ from autumn to winter, as well as edoxaban tosilate hydrate $\left(\right.$ Lixiana $\left.{ }^{R}\right) 30 \mathrm{mg}$. Concerning the medication of Nifedipine, the reason is from her situation that she showed lower BP in summer and higher BP in winter. 
For current hospitalization, her prescription was changed to the following and will be continued after discharge. They include i) amlodipine besilate (Amlodine ${ }^{\mathrm{R}}$ ) $5 \mathrm{mg} 1 \mathrm{~T}$, ii) enalapril maleate $\left(\right.$ Renivace $\left.^{\mathrm{R}}\right) 5 \mathrm{mg} 1 \mathrm{~T}$, iii) edoxaban tosilate hydrate $\left(\right.$ Lixiana $\left.{ }^{\mathrm{R}}\right) 30 \mathrm{mg} 1 \mathrm{~T}$, iv) lansoprazole $\left(\right.$ Takepron $^{\mathrm{R}}$ ) $15 \mathrm{mg} 1 \mathrm{~T}, \mathrm{v}$ ) spironolactone (Aldactone $\mathrm{A}^{\mathrm{R}}$ ) 25mg 1T, vi) Levothyroxine Sodium Hydrate (Thyradin $\mathrm{S}^{\mathrm{R}}$ ) $25 \mu \mathrm{g}$, vii) tolvaptan $\left(\right.$ Samska $\left.^{R}\right)$.

\section{Clinical progress}

This case has remained stable since discharge and has been monitored on an outpatient basis. Regarding clinical problems, no particular symptoms are observed such as chest discomfort, exertional dyspnea, nausea, or abdominal pain. Chest X-P and electrocardiogram are also unchanged. Regarding the examination data, improvements of the results are found. On discharge, $\mathrm{Hb} 9.8 \mathrm{~g} / \mathrm{dL}$ and MCV 65.2fL were observed, and these data became $\mathrm{Hb} 11.5 \mathrm{~g} / \mathrm{dL}$ and MCV 79.3fL after 7 weeks. For iron metabolism, serum iron levels increased from $9 \mu \mathrm{g} / \mathrm{dL}$ to $118 \mu \mathrm{g} / \mathrm{dL}$, and serum ferritin levels increased from $4.3 \mathrm{ng} /$ $\mathrm{mL}$ to $40 \mathrm{ng} / \mathrm{mL}$ (Table 1 ).

The overall view of clinical progress in this case is drawn in Figure 3. The $\mathrm{Hb}$ level was temporarily decreased, but it has returned to almost the previous level with the administration of iron preparations. She was hospitalized and treated, and her fatigue and edema disappeared. Currently, she has continued to take ferrous citrate, tolvaptan and levothyroxine, with consecutively observing the clinical progress.

Table I Changes in several biomarkers

\begin{tabular}{|c|c|c|c|c|c|c|c|c|c|c|c|c|c|}
\hline \multirow{2}{*}{ Category } & \multirow{2}{*}{ Marker } & \multirow{2}{*}{ Unit } & \multicolumn{2}{|l|}{2019} & \multicolumn{4}{|l|}{2020} & \multicolumn{5}{|l|}{2021} \\
\hline & & & Mar & Oct & April & Sept & 5-Nov & I4-Nov & 4-Feb & 8-Feb & I6-Feb & 2-Mar & 30-Mar \\
\hline \multirow[t]{8}{*}{$\mathrm{CBC}$} & WBC & $(/ \mu \mathrm{L})$ & & & & & & 4500 & 5700 & & 6100 & 5700 & 6400 \\
\hline & RBC & $(x \mid 0 * 4 / \mu \mathrm{L})$ & 451 & 416 & 415 & 290 & & 356 & 428 & & 489 & 519 & 467 \\
\hline & $\mathrm{Hb}$ & $(\mathrm{g} / \mathrm{dL})$ & 12.1 & 11.6 & 11.2 & 5.2 & & 5.3 & 7.5 & 9.8 & 10.4 & II.3 & 11.5 \\
\hline & $\mathrm{Hct}$ & $(\%)$ & 38.9 & 37 & 36.3 & 18.6 & & 19.4 & 27.9 & 35.8 & 35.9 & 38.6 & 37.1 \\
\hline & $\mathrm{MCV}$ & $(\mathrm{fL})$ & 86 & 89 & 88 & 64 & & 54.5 & 65.2 & & 73.4 & 74.4 & 79.3 \\
\hline & $\mathrm{MCH}$ & (pg) & 26.8 & 27.9 & 27 & 17.9 & & 14.8 & 17.5 & 19.3 & 21.2 & 21.8 & 24.5 \\
\hline & $\mathrm{MCHC}$ & $(g / d L)$ & 31.1 & 31.4 & 30.9 & 28 & & & & & 28.9 & 29.3 & 30.9 \\
\hline & Plt & $(x \mid 0 * 4 / \mu \mathrm{L})$ & 32.2 & 28.3 & 29.6 & 36.2 & & 38.7 & 33.7 & & 28.7 & 28.8 & 29.2 \\
\hline \multirow[t]{4}{*}{ Fe Metab } & $\mathrm{Fe}$ & $(\mu g / d L)$ & & & & & 9 & & & & 118 & & \\
\hline & UIBC & $(\mu g / d L)$ & & & & & 392 & & & & & & \\
\hline & TIBC & $(\mu g / d L)$ & & & & & 401 & & & & & & \\
\hline & Ferritin & $(\mathrm{ng} / \mathrm{mL})$ & & & & & 4.3 & & & & 40 & & \\
\hline \multirow[t]{4}{*}{$\begin{array}{l}\text { renal } \\
\text { function }\end{array}$} & BUN & (mg/dL) & 12 & 18 & 12 & 14 & & & 22 & & 8 & 16 & \\
\hline & $\mathrm{Cr}$ & (mg/dL) & 0.7 & 0.6 & 0.6 & 0.6 & & & 0.6 & & 0.5 & 0.7 & \\
\hline & $\mathrm{Na}$ & $(\mathrm{mEq} / \mathrm{L})$ & $|4|$ & 142 & 142 & 142 & & & 148 & & 148 & 144 & \\
\hline & $\mathrm{K}$ & $(\mathrm{mEq} / \mathrm{L})$ & 4.7 & 4.3 & 4.6 & 4 & & & 3.7 & & 4.6 & 4.9 & \\
\hline \multirow[t]{6}{*}{ Thyroid } & free $T 3$ & $(\mathrm{pg} / \mathrm{mL})$ & & & & & & & 1.9 & & & 2.7 & \\
\hline & free $T 4$ & (ng/dL) & & & & & & & I.I & & & I.I & \\
\hline & TSH & $(\mu \mathrm{lU} / \mathrm{mL})$ & & & & & & & 9.4 & & & 2.4 & \\
\hline & $\operatorname{TgAb}$ & $(+/-)$ & & & & & & & $<100 x$ & & & & \\
\hline & ATMA & $(+/-)$ & & & & & & & $<100 x$ & & & & \\
\hline & TRAb & $(+/-)$ & & & & & & & $(-)$ & & & & \\
\hline \multirow[t]{5}{*}{ Metab Nutr } & AST & $(\mathrm{U} / \mathrm{L})$ & 28 & 31 & 36 & 24 & & & 42 & & 41 & 36 & \\
\hline & $\mathrm{ALT}$ & $(\mathrm{U} / \mathrm{L})$ & 15 & 17 & 18 & 11 & & & 31 & & 32 & 28 & \\
\hline & TP & $(\mathrm{g} / \mathrm{dL})$ & 7.7 & 7.4 & 7.5 & 6.9 & & & 7.2 & & 8.1 & & \\
\hline & Alb & $(g / d L)$ & 4.2 & 4.2 & 4.2 & 3.7 & & & 3.7 & & 3.4 & & \\
\hline & $\mathrm{HbAlc}$ & $(\%)$ & & & & & & & 5.5 & & & 5.2 & \\
\hline \multirow[t]{4}{*}{ Others } & CRP & (mg/dL) & 0.03 & 0.01 & 0.03 & 0.01 & & & 0.6 & & & & \\
\hline & CEA & $(\mathrm{ng} / \mathrm{mL})$ & & & & & 1.5 & & & & & & \\
\hline & $\begin{array}{l}\text { NT- } \\
\text { ProBNP }\end{array}$ & (pg/mL) & & & & & & & 2596 & & & 163 & \\
\hline & $\begin{array}{l}\text { TgAB: thy } \\
\text { antibody }\end{array}$ & bulin anti & ATI & nti & id mic & mal a & ody, TR & nti-TS & ceptor & & & & \\
\hline
\end{tabular}




\section{Discussion}

Regarding this case, a variety of data were obtained. According to Table 1, the case did not have remarkable abnormalities in renal function, liver function or diabetes. The cause of current anemia was not clarified, but the results of CRP, CEA, and endoscopic exams suggested that the case was unlikely to have a malignant disease. A small dose of thyroid hormone was started, and the values of free $\mathrm{T}_{3}$, free $\mathrm{T}_{4}$ and TSH were normalized. Furthermore, improvement of anemia seemed to be promoted by the supplementation of thyroid hormone (Figure 3).

In this report, some perspectives will be presented in three main aspects. They are i) thyroid function and its supplementation dose, ii) relationship among thyroid function, anemia and edema, and iii) cardiovascular function and anemia, which are described in order as follows.

I suggest connecting the cause of anemia with hypothyroidism, as the latter known to cause anemia and the authors may have a look at previous studies. In addition, the authors mentioned that the hypothyroidism therapy result in improvement of anemia state and this may reinforce this suggestion.

Firstly, primary hypothyroidism is more popular than secondary hypothyroidism from the genesis point of view. In the case of central (secondary and tertiary) hypothyroidism, several causes are found such as congenital or acquired hypopituitarism, lymphocytic hypophysitis, pituitary apoplexy and other hypothalamic disorders. The treatment includes the administration of levothyroxine. The doses for replacement for primary hypothyroidism would be $1.6-1.8 \mathrm{mg} / \mathrm{kg} /$ day for young to middle-age cases, and that for central hypothyroidism is $1.3 \mathrm{mg} / \mathrm{kg} /$ day with lower required amount. ${ }^{11}$ In current case, lower doses were provided because of higher age and slight reduction of free $\mathrm{T}_{3}$ and $\mathrm{T}_{4}$ and slight elevation of TSH value.

Secondly, she has generalized edema on admission that has been called as anasarca. For necessary rapid effective treatment, tolvaptan $\left(\right.$ Samska $\left.{ }^{\mathrm{R}}\right)$ was provided. ${ }^{12}$ It is an oral and novel nonpeptide vasopressin V2-receptor antagonist, which is used for chronic heart failure (CHF). Regarding this agent, a double-blind study was conducted in 254 subjects for 4 groups. They included placebo, tolvaptan 30mg, $45 \mathrm{mg}$, and $60 \mathrm{mg}$ provided for 25 days. The results showed weight changes as $+0.32 \mathrm{~kg},-0.79 \mathrm{~kg},-0.96 \mathrm{~kg}$, and $-0.84 \mathrm{~kg}$, respectively with significant difference. Clinical efficacy was enough for weight reduction, reduced edema, normalized serum sodium level. ${ }^{12}$

Recent report showed a female patient with primary hypothyroidism, which has bilateral pleural effusion. ${ }^{13}$ Such case associated both of hypothyroidism and pleural effusion has been rather rare, and the supplementation of oral levothyroxine tablets 50 $\mu \mathrm{g}$ per day brought her the improvement of the diseased situation. Consequently, physicians had better pay attention to the combination of clinical symptoms in order to avoid misdiagnosis and mistreatment. ${ }^{13}$

Hypothyroidism can bring both possibility of exudative effusion or transudative effusion. ${ }^{14}$ So far, there have been few investigations concerning the pathogenesis of pleural effusion from the influence of hypothyroidism. Its pathophysiology may be involved in the elevated capillary permeability due to the reduced blood values of thyroxine. ${ }^{15}$ Previous studies have indicated that thyroid hormone may influence the expression of VEGF (vascular endothelial growth factor). ${ }^{16}$ Then hypothyroidism may cause elevation of VEGF value in the pleural effusion. Hypothyroidism may also bring the rapid increase of capillary permeability. On the other hand, administration of supplementary oral thyroxine can gradually reduce local VEGF level and decrease the amount of pleural effusion. ${ }^{17}$ This improvement may be from the mechanism that VEGF is involved with the regulating function of capillary permeability in the case of hypothyroidism.

Further, this case has shown improved anemia after the administration of levothyroxine. This response would be the correlation between hypothyroidism and anemia.

Thirdly, regarding the combined problems of cardiovascular and anemia, some perspectives can be observed. ${ }^{18}$ In patients with heart failure (HF), iron deficiency (ID) may correlate with reduced performance of activities of daily living (ADL) and poor health-related quality of life (QOL). Oral iron supplementation is not effective for iron deficiency patients with $\mathrm{HF}$ and reduced ejection fraction. On the other hand, intravenous administration of iron therapy would be shown to relieve HF symptoms and improve ADL and QOL of the patient. $^{18}$

Comparing this description with current case in this report, the pathophysiological situation seems to be opposite. In this case, there were no symptoms or signs of heart failure in the past, and anemia was developed for uncertified reason. While the anemia was gradually improving after the administration of iron preparations, systemic edema was developed. Furthermore, treatment of diuresis after admission has improved the anemia in rather short period.

Academic literatures were searched for anemia, edema, anasarca, and ferrous citrate as the keywords. As a result, one report suggesting these relationships was found. ${ }^{19}$ The case was 13-month-old girl who developed progressive anasarca edema. For several months she had consumed large amounts of fresh cow's milk. On admission, severe iron deficiency anemia (IDA) associated with hypochromic anemia $(\mathrm{Hb} 3.8 \mathrm{~g} / \mathrm{dL})$ and reduced ferritin level was found. For further evaluation and treatment, absence of allergy for milk and successful treatment of intravenous iron sucrose were observed. ${ }^{19}$

Some limitations are present in this report. The cause of her subacute anemia was investigated, but the endoscopic examination and laboratory data were negative. There is a possibility of relationship with thyroid function and others. Other medical problems include higher age of the patient, and adequate administration of medicines for thyroid hormone and cardiovascular control. Our medical team will follow up the detail progress with attention.

In summary, an 85-year-old woman showed an impressive clinical progress. In other words, anemia, edema, and heart failure occurred, followed by the existence of hypothyroidism clarified, and then clinical situation was improved by administration of thyroid hormone. Some discussion was described on the relationship among thyroid function, edema, cardiac function and anemia. Authors hope that this article will serve as a reference for pathophysiological investigations with a wide range of fields.

\section{Acknowledgments}

None.

\section{Funding}

There was no funding received for this paper.

\section{Conflicts of interest}

The authors declare no conflict of interest. 


\section{References}

1. Grishina NK, Perepelova OV, Solovieva NB. The implementation of complex of measures targeting support of patient-oriented principle under organization of paid medical services. Probl Sotsialnoi Gig Zdravookhranenniiai Istor Med. 2021;29(1):120-124.

2. Buse JB, Holst I, Knop FK, et al. Prototype of an evidence-based tool to aid individualized treatment for type 2 diabetes. Diabetes Obes Metab. 2021.

3. Sakamoto D, Bando H, Iwatsuki N, et al. Remarkable improvement of periodontal diseases (PD) and diabetic state with weight reduction by super low carbohydrate diet (LCD). J Oral Dent Health Res. 2020;2(2):114.

4. Bando H, Abe Y, Sakamoto K, et al. Profile of blood glucose in diabetic patient suffered from diabetic foot osteomyelitis with effective low carbohydrate diet. Diabetes Res Open J. 2020;6(1):10-16.

5. Iwatsuki N, Bando H. Pharmacological influences of oral hypoglycemic agents (OHAs) for liver function. International Med. 2021;3(1):1-3.

6. Wang CS, Greenbaum LA. Nephrotic Syndrome. Pediatr Clin North Am. 2019;66(1):73-85.

7. Bonney KM, Luthringer DJ, Kim SA, et al. Pathology and pathogenesis of chagas heart disease. Annual Review of Pathology. 2019;14:421-447.

8. Wang G, Cao WG, Zhao TL. Fluid management in extensive liposuction: A retrospective review of 83 consecutive patients. Medicine. 2018;97(41):e12655.

9. Kumar G, Kumar A, Bundela RP, et al. Hypothyroidism presenting as multiple body cavity effusions. J Assoc Physicians India. 2016;64(7):8384

10. Lee JH, Park M, Park MJ, et al. Massive pleural and pericardial effusion due to hypothyroidism in a patient with a surgically treated thyroidstimulating hormone-producing pituitary adenoma. Acta Clin Belg. 2018;73(5):398-401.
11. Trifanescu RA, Poiana C. Diagnosis and management of hypothyroidism in adults. In: Llahana S, Follin C, Yedinak C, editors. Advanced Practice in Endocrinology Nursing. Springer, Cham; 2019.

12. Gheorghiade M, Niazi I, Ouyang J, et al. Vasopressin V2-receptor blockade with tolvaptan in patients with chronic heart failure: results from a double-blind, randomized trial. Circulation. 2003;107(21):2690 2696.

13. Yuan G, Yan Q, He M. A case of pleural effusion caused by hypothyroidism. Journal of Biosciences and Medicines 2020;8:1-4.

14. He YX, Xue B. Misdiagnosis and mistreatment of hypothyroidism with pleural effusion. Clinical Misdiagnosis and Mistreatment. 2008;31:2224.

15. Korayem AH, Mujica PE,Aramoto H, et al. Endothelial cAMP deactivates ischemia-reperfusion-induced microvascular hyperpermeability via Rap1-mediated mechanisms. Am J Physiol Heart Circ Physiol. 2017;313(1):H179-H189.

16. Li J, Teng L, Jiang H. Relationship between preoperative serum TSH levels and expression of VEGF in papillary thyroid carcinoma. Asia Pac $J$ Clin Oncol. 2014;10(2):149-152.

17. Hataya Y, Akamizu T, Kanamoto N, et al. A case of subclinical hypothyroidism developing marked pleural effusions and peripheral edema with elevated vascular endothelial growth factor. Endocr J. 2007;54(4):577-584.

18. Drozd M, Jankowska EA, Banasiak W, et al. Iron therapy in patients with heart failure and iron deficiency: review of iron preparations for practitioners. Am J Cardiovasc Drugs. 2017;17(3):183-201.

19. Mantadakis E, Zikidou P, Tsouvala E, et al. Severe iron deficiency anemia and anasarca edema due to excessive cow's milk intake. Turk $J$ Pediatr. 2019;61:102-106. 